\title{
Night time performance of a storage integrated solar thermophotovoltaic (SISTPV) system
}

\author{
A. Veeraragavan , L. Montgomery , A. Datas
}

\begin{abstract}
Energy storage at low maintenance cost is one of the key challenges for generating electricity from the solar energy. This paper presents the theoretical analysis (verified by CFD) of the night time performance of a recently proposed conceptual system that integrates thermal storage (via phase change materials) and thermophotovoltaics for power generation. These storage integrated solar thermophotovoltaic (SISTPV) systems are attractive owing to their simple design (no moving parts) and modularity compared to conventional Concentrated Solar Power (CSP) technologies. Importantly, the ability of high temperature operation of these systems allows the use of silicon (melting point of $1680 \mathrm{~K}$ ) as the phase change material (PCM). Silicon's very high latent heat of fusion of $1800 \mathrm{~kJ} / \mathrm{kg}$ and low cost $(\$ 1.70 / \mathrm{kg})$, makes it an ideal heat storage medium enabling for an extremely high storage energy density and low weight modular systems. In this paper, the night time operation of the SISTPV system optimised for steady state is analysed. The results indicate that for any given PCM length, a combination of small taper ratio and large inlet hole-to-absorber area ratio are essential to increase the operation time and the average power produced during the night time. Additionally, the overall results show that there is a trade-off between running time and the average power produced during the night time. Average night time power densities as high as $30 \mathrm{~W} / \mathrm{cm}^{2}$ are possible if the system is designed with a small PCM length $(10 \mathrm{~cm})$ to operate just a few hours after sun-set, but running times longer than $72 \mathrm{~h}$ ( 3 days) are possible for larger lengths $(50 \mathrm{~cm})$ at the expense of a lower average power density of about $14 \mathrm{~W} / \mathrm{cm}^{2}$. In both cases the steady state system efficiency has been predicted to be about $30 \%$. This makes SISTPV systems to be a versatile solution that can be adapted for operation in a broad range of locations with different climate conditions, even being used off-grid and in space applications.
\end{abstract}

Keywords: Solar energy; Thermal storage; Phase change material; Photovoltaics; Concentrating solar power; Solar thermophotovoltaics

\section{Introduction}

Storage integrated solar thermophotovoltaics (SISTPV) systems were firstly proposed in the mid 90s (Stone et al., 1995, 1994a,b, 1996) as candidates to substitute the more mature Concentrated Solar Power (CSP) technologies for the thermal storage and conversion of the solar energy into electricity. Unlike CSP systems, SISTPV systems use photovoltaic (PV) cells to directly convert radiative heat into electricity. The main advantage of SISTPV systems when compared to conventional CSP systems is their simple design which uses no moving parts or working fluids to convert heat into electricity. This reduces the maintenance cost, which is one of the main handicaps of CSP technologies when compared with photovoltaic (PV) systems.

The operating principle of a SISTPV system is simple (Bauer, 2011; Chubb, 2007; Catalano, 1996): an incandescent material, heated by concentrated sunlight, radiates 


\begin{tabular}{|c|c|c|c|}
\hline \multicolumn{4}{|c|}{ Nomenclature } \\
\hline$c$ & speed of light $(\mathrm{m} / \mathrm{s})$ & $\rho$ & density $\left(\mathrm{kg} / \mathrm{m}^{3}\right)$ \\
\hline$h$ & Planck's constant $\left(\mathrm{m}^{2} / \mathrm{kg} \mathrm{s}\right)$ & & \\
\hline$k$ & thermal conductivity $\left(\mathrm{W} / \mathrm{m}^{2}\right)$ & \multicolumn{2}{|c|}{ Subscripts } \\
\hline$t$ & time $(\mathrm{h})$ & & \\
\hline$x$ & spatial coordinate along length of tank $(\mathrm{cm})$ & $\begin{array}{l}a \\
a v g\end{array}$ & $\begin{array}{l}\text { absorber } \\
\text { average }\end{array}$ \\
\hline$A$ & cross sectional area $\left(\mathrm{cm}^{2}\right)$ & & PV cell area \\
\hline$A R$ & ratio of the absorber area to the inlet hole area & $e$ & Emitter \\
\hline$C_{p}$ & $\begin{array}{l}(-) \\
\text { specific heat capacity at constant pressure } \\
(\mathrm{J} / \mathrm{kg} \mathrm{K})\end{array}$ & $\begin{array}{l}\text { end } \\
h \\
\text { in }\end{array}$ & $\begin{array}{l}\text { end of solidification time } \\
\text { inlet hole } \\
\text { input to PCM tank }\end{array}$ \\
\hline$E$ & energy of photon $(\mathrm{J})$ & lis & liguid \\
\hline$J$ & current density $\left(\mathrm{Amps} / \mathrm{cm}^{2}\right)$ & & melting point \\
\hline$L$ & $\begin{array}{l}\text { length of phase change material }(\mathrm{PCM}) \text { tank } \\
(\mathrm{cm})\end{array}$ & & solid \\
\hline$L_{f}$ & latent heat of fusion $(\mathrm{kJ} / \mathrm{kg})$ & $B S R$ & backside reflector \\
\hline$N$ & number of photons $(-)$ & $G$ & bandgap \\
\hline$P$ & power $\left(\mathrm{W} / \mathrm{m}^{2}\right)$ & & \\
\hline $\begin{array}{l}Q \\
T\end{array}$ & heat flux $(\mathrm{W})$ & \multicolumn{2}{|c|}{ Superscripts } \\
\hline$T R$ & taper ratio or emitter to absorber area ratio $(-)$ & . & rate of change with time \\
\hline$X$ & melting line $(\mathrm{cm})$ & "I & per unit area \\
\hline
\end{tabular}

towards a photovoltaic (PV) cell which directly produces electricity. The key aspect of the design is the option of integrating a phase-change material (PCM), in which a solid is melted, capturing and storing a considerable amount of thermal energy as latent heat. In this arrangement, the PV cells can have a back side reflector (BSR) that reflects back to the emitter the non-absorbed radiation (mainly the subbandgap photons) enabling an extremely high PV conversion efficiency (much higher than conventional solar PV cells (Datas and Algora, 2010, 2012; Datas et al., 2013; Gartling, 1978; Gau and Viskanta, 1984). As explained elsewhere (Bauer, 2011; Chubb, 2007), TPV technology has a great potential to boost the heat-to-electricity conversion efficiency, even above $50 \%$. As a reference, the best reported experimental efficiency up to date was reported in 2004 and it is of $23.6 \%$ at $1039^{\circ} \mathrm{C}$ emitter temperature (Wernsman et al., 2004). With more recent advanced TPV systems investigating the use of photonic crystals to improve the system's efficiency (Lenert et al., 2014). The main advantage SISTPV systems offer over PV is the thermal storage which (1) overcomes the intermittency inherent to PV and concentrated PV (CPV) systems and (2) enables electricity production to match the peak demand (i.e. grid demand which peaks in the residential domain in the evenings).

Early SISTPV designs (Stone et al., 1994a,b, 1995, 1996) were conceived more as experimental test-bed units rather than fully optimised systems, and consequently their potential was fundamentally limited. More recent works (Chubb et al., 1996; Datas et al., 2013; Gilpin et al., 2011; Scharfe et al., 2011) have proposed improved conceptual SISTPV system designs with greater potential in terms of efficiency and storage ability. One of the main characteristics of these kinds of SISTPV systems is the use of very high melting point phase change materials (PCM). In Gilpin et al. (2011) and Scharfe et al. (2011) ultra-high melting point $(2350 \mathrm{~K})$ and heat of fusion $(4600 \mathrm{~kJ} / \mathrm{kg}$ ) Boron PCM has been devised for being used in the solar thermal propulsion of microsatellites. However, its application in terrestrial applications is unlikely owing to cost and compatibility issues. For terrestrial applications, however, silicon has been identified as the ideal candidate (Chubb et al., 1996; Datas et al., 2013; Gilpin et al., 2011; Scharfe et al., 2011). This is mainly because of its very high heat of fusion $(1800 \mathrm{~kJ} / \mathrm{kg}$ ) and low price (about $\$ 1.70 / \mathrm{kg}$ which translates to $\$ 0.95 \mathrm{MJ} / \mathrm{kg}$ (Gilpin et al., 2011). Silicon is also one of the most abundant materials on earth. When compared with conventional CSP systems using molten salts, the use of silicon allows much longer running times in the dark with a small amount of silicon which allows the building of compact low weight systems. Silicon cannot be used in conventional CSP systems due to the extremely high melting temperature, which adds reliability issues at the heat transfer fluid (HTF). Conversely, this temperature is perfectly suitable for the fluid-less thermophotovoltaic technology.

In our previous work (Datas et al., 2013), we presented a full optimisation of a silicon-based SISTPV system in the steady state. The key characteristic of this system is the tapered configuration for the PCM tank which allows the proper melting of the full PCM and enhancement of the conversion efficiency simultaneously. We performed a direct search of several configuration parameters to find 
the best system performance in terms of efficiency and storage energy density. We concluded that efficiencies of about $\sim 30 \%$ are attainable by using the full latent heat potential of Silicon $(1800 \mathrm{~kJ} / \mathrm{kg})$ using single junction PV cells. However, in order to evaluate the SISTPV system for a full day/ night cycle, it is critical to calculate the performance for night time operation. Therefore, it is the objective of this paper to analyse the night time operation of SISTPV systems optimised in Datas et al. (2013) for the steady state. We assume a quasi-stationary approach to model the transient response of the system after sunset. This approach implies assuming a stationary interface within each time interval, at which the system is modelled similar to the steady state (Datas et al., 2013). A time marching scheme is introduced based broadly on the enthalpy balance method (Alexiades and Solomon, 1993; Brent et al., 1988; $\mathrm{Hu}$ and Argyropoulos, 1996) to account for the transient nature of the night time operation.

As in Datas et al. (2013), the PV cells will be modelled in the framework of the detailed balance theory (Shockley and Queisser, 1961; Araújo and Martí, 1994; Datas and Algora, 2010, 2012; Datas et al., 2013) and assuming that the only recombination mechanism that takes place is radiative. A simplified $1 \mathrm{D}$ model for the heat transfer in the PCM will be used following reference (Chubb et al., 1996). In this model, natural convection in liquid silicon is neglected. This is a good assumption because the PCM container is kept vertical and heated from above. The configuration of the day time operation was presented in Datas et al. (2013), in which the solar receiver is mounted on a sun-tracking system which is then coupled to the PCM tank which is always kept vertical. Therefore, the analysis presented in the previous work (Datas et al., 2013) as well as in the present formulation only considers a vertical tank with constant solar concentration for day time operation and zero solar input for night time. It is also worth noting that natural convection within the PCM will result in improved heat transfer, which means that the configuration analysed in this paper represents a conservative estimate for the heat transfer within the PCM tank. The assumptions made in the simplified model are verified against detailed 3D CFD simulations that also account for buoyancy effects. Further improvements could be achieved using more sophisticated strategies, such as the inclusion of fins or heat pumps (Huang et al., 2011; Lamberg and Siren, 2003) within the PCM, but such advance modelling is beyond the scope of this paper.

This study broadens the understanding of the influence of the system design variables on the performance of the SISTPV system during the night time and provides general guidelines to designing practical systems in the near future.

\section{System description and formulation}

The system was described in detail in previous work (Datas et al., 2013) where the SISTPV design was optimised for steady state. We briefly repeat it here for completeness.

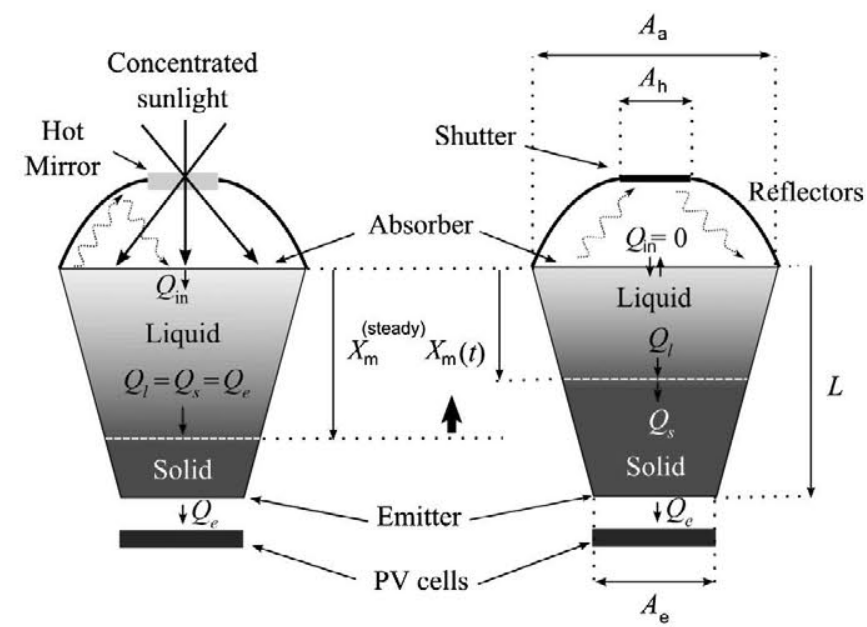

(a) Day operation

(steady state) (b) Night operation

(transient)
Fig. 1. (a) SISTPV system in daytime operation when the hole is open and receives concentrated solar radiation and (b) night time operation with hole closed by reflecting shutter with the liquid silicon solidifying to provide the heat for the thermophotovoltaics shown as emitter/PV cells in the figure.

\subsection{SISTPV description}

The SISTPV system configuration analysed in this paper is shown in Fig. 1. The concentrated sunlight passes through a spectrally selective filter (labelled hot mirror), located at the inlet hole of the absorber cavity. The filter transmits (reflects) the photons with energies higher (lower) than some specific threshold value $\varepsilon_{c a}$ (Datas and Algora, 2010,2012 ). This is done to avoid excessive radiation losses from the absorber (Kennedy, 2002) as the incoming solar power in these frequencies is lesser than the radiative losses $\varepsilon_{c a}$ was optimised in the steady state calculations performed previously (Datas et al., 2013). The absorber cavity walls are assumed to be perfectly reflective and insulated, which ensures that all the incoming energy is transferred to the absorber surface. The PCM is located in between the absorber and the emitter surfaces (Fig. 1b) and is contained in a tapered tank. Past research has shown that the tapered configuration allows the proper melting of the PCM (Chubb et al., 1996). The solar insolation absorbed is converted to heat and conducted through the PCM (and in the process potentially melting the PCM) to the emitter, where it is radiated to the PV cells. Therefore, the PCM has a temperature profile with a higher temperature at the absorber side $\left(T_{a}\right)$ than at the emitter $\left(T_{e}\right)$. The PCM stores energy as latent heat of fusion when $T_{a}$ exceeds the melting temperature of the PCM $\left(T_{m}\right)$ and the storage energy density by latent heat (total stored latent heat divided by the total PCM weight) reaches its maximum when all the PCM is melted $\left(T_{e} \geqslant T_{m}\right.$ and $X_{m}=L$ in Fig. 1).

At the emitter/PV cells side, we assume a black body emitter and single junction PV cells with back-side reflectors (BSR) (Wilt et al., 2003; Huang et al., 2004) as was 
done in earlier work (Datas and Algora, 2010, 2012; Datas et al., 2013). The BSR reflects the photons that are not absorbed by the PV cells, i.e. the photons with energies below the bandgap. Note that for this arrangement to be effective, it is essential to have very low free carrier absorption within the bulk of the semiconductor PV cell substrate. Some materials like InP show very low free carrier absorption and consequently, have been used as the substrate to manufacture TPV cells with BSR (Wilt et al., 2003). Another very promising approach to manufacture such cells is to use thin film PV cells on highly reflective substrates (Wilt et al., 2003; Huang et al., 2004).

\subsection{Semi-analytical formulation}

The analysis of the day-operation (steady state) of this system was presented in our previous work (Datas et al., 2013), where the heat fluxes along with the produced electricity were calculated for the steady state. The steady state results from Datas et al. (2013) provided a clear understanding of which geometric choices $(A R, T R)$ resulted in the complete melting of the PCM tank as well as where the system's efficiency was maximised. For the night time study, we have carefully selected geometric choices for a fixed solar concentration of $C=1000$ that provide a fully melted PCM tank in the steady state, i.e. $X_{m}=L$ and $T_{e}=T_{m}$. This ensures that the latent heat storage capacity of the PCM tank is fully utilised. This analysis further assumes that at twilight the solar receiver is decoupled from the PCM tank (causing the solar input to drop to zero), whereupon the latent heat stored in the PCM tank continues to power the TPV system. Table 1 shows the conditions from the starting steady state calculations that will be analysed for night time performance. Note that the TPV efficiency $\left(\eta_{T P V}\right)$ is nearly constant, varying in 3rd decimal which is not shown in the table, for the day time cases chosen here owing to the emitter temperature being equal (to the melting temperature $T_{m}$ ).

At night, the hot mirror is replaced by a reflecting mirror (the shutter in Fig. 1) to prevent heat losses from the absorber surface. In the present formulation we assume this means no heat is lost from the absorber in the night time. The absence of input power $\left(Q_{\text {in }}=0\right.$ in Fig. 1) results in a transition from a steady to an unsteady heat transfer problem. During this period, all the heat fluxes, temperatures as well as the position of solid-liquid interface are changing in time.

To describe the evolution of temperature and heat fluxes in the PCM storage tank we adopt the quasi-stationary approach used in previous work by Hsieh (1995) and described in Alexiades and Solomon (1993). Owing to silicon's high latent heat of fusion, the quasi-stationary approach is reasonably accurate as the movement of the interface is expected to be slow. As done in our previous work (Datas et al., 2013), we assume a quasi-1D model in which the solid/liquid interface is a plane at $x=X_{m}$. Under these assumptions, the quasi-1D Fourier law can be used to describe the quasi-stationary conductive heat transfer at each time step through the liquid and solid PCM as:

$\dot{Q}_{l, s}(t)=-k_{l, s} A(x) \frac{d T_{l, s}}{d x}$

$\dot{Q}_{l, s}(t)=\dot{Q}_{l, s}^{\prime \prime}(x, t) \times A(x)= \begin{cases}\dot{Q}_{a}^{\prime \prime}(t) \times A_{a}, & \text { Liquid } \\ \dot{Q}_{e}^{\prime \prime}(t) \times A_{e}, & \text { Solid }\end{cases}$

$A(x)=A_{a}(1+T R-2 \sqrt{T R})\left(\frac{x}{L}-\frac{1}{1-\sqrt{T R}}\right)^{2}$

$\dot{Q}_{l, s}$ is the heat (in Watts) transferred thorough the liquid or solid respectively given by Eq. (2) above, where the subscripts $a$ stands for absorber and $e$ stands for emitter. The transferred heat varies with time but is assumed constant at any given time instant, allowing for expressing Eq. (1) in terms of only the spatial coordinate $(x)$. These assumptions and the model are verified against a CFD solver subsequently in Section 3.2 of the paper. $A(x)$ is the cross-sectional area, assumed to be square, of the PCM tank as a function of coordinate position $x$. The parameter $T R=A_{e} / A_{a}$ is the emitter to absorber area ratio or tapering ratio, $A_{a}$ is the absorber area and $L$ is the length

Table 1

Day time performance metrics in steady state for $C=1000\left(T_{e}=T_{m}\right.$ in all the cases).

\begin{tabular}{|c|c|c|c|c|c|c|c|c|c|c|}
\hline$L(\mathrm{~cm})$ & $A R(-)$ & $T R(-)$ & $E_{c a}(\mathrm{eV})$ & $E_{\text {gap }}(\mathrm{eV})$ & $T_{a}(\mathrm{~K})$ & $P_{d}\left(\mathrm{~W} / \mathrm{cm}^{2}\right)$ & $P_{d} \times A_{d} / A_{h}\left(\mathrm{~W} / \mathrm{cm}^{2}\right)$ & $\eta_{a b s}(-)$ & $\eta_{T P V}(-)$ & $\eta_{\text {system }}(-)$ \\
\hline 10 & 10 & 0.45 & 0.92 & 0.51 & 1961 & 10.4 & 44.40 & 0.71 & 0.41 & 0.29 \\
\hline 10 & 30 & 0.17 & 0.83 & 0.54 & 1843 & 9.8 & 47.28 & 0.76 & 0.41 & 0.31 \\
\hline 10 & 100 & 0.05 & 0.78 & 0.52 & 1772 & 10.2 & 48.62 & 0.78 & 0.41 & 0.32 \\
\hline 20 & 10 & 0.40 & 1.10 & 0.53 & 2193 & 10.1 & 38.27 & 0.61 & 0.41 & 0.25 \\
\hline 20 & 30 & 0.14 & 0.95 & 0.50 & 2005 & 10.8 & 43.24 & 0.71 & 0.41 & 0.29 \\
\hline 20 & 100 & 0.05 & 0.84 & 0.53 & 1860 & 9.9 & 46.83 & 0.76 & 0.41 & 0.31 \\
\hline 30 & 10 & 0.32 & 1.29 & 0.50 & 2400 & 10.5 & 31.88 & 0.51 & 0.41 & 0.21 \\
\hline 30 & 30 & 0.13 & 1.06 & 0.51 & 2141 & 10.7 & 39.76 & 0.63 & 0.41 & 0.26 \\
\hline 30 & 100 & 0.05 & 0.92 & 0.53 & 1947 & 9.4 & 44.88 & 0.73 & 0.41 & 0.30 \\
\hline 40 & 10 & 0.27 & 1.45 & 0.50 & 2557 & 10.4 & 26.68 & 0.44 & 0.41 & 0.18 \\
\hline 40 & 30 & 0.13 & 1.16 & 0.53 & 2258 & 9.8 & 36.36 & 0.59 & 0.41 & 0.24 \\
\hline 40 & 100 & 0.04 & 0.96 & 0.53 & 2023 & 11.3 & 42.88 & 0.68 & 0.41 & 0.28 \\
\hline 50 & 10 & 0.22 & 1.58 & 0.51 & 2680 & 10.7 & 22.36 & 0.37 & 0.41 & 0.15 \\
\hline 50 & 30 & 0.11 & 1.26 & 0.52 & 2371 & 10.5 & 32.85 & 0.54 & 0.41 & 0.22 \\
\hline 50 & 100 & 0.04 & 1.04 & 0.50 & 2110 & 10.7 & 40.51 & 0.66 & 0.41 & 0.27 \\
\hline
\end{tabular}


of the PCM tank. The steady state optimisation done previously in Datas et al. (2013) also investigated the effect of the absorber area to inlet hole area $\left(A R=A_{a} / A_{h}\right.$, see Fig. 1) ratio which will be used here to explore the night time performance of those conditions.

In steady state (Datas et al., 2013), the heat conduction through the solid and liquid are equal and the interface is stationary. However, during the night operations the heat conduction through the solid and liquid regions are different as the absorber no longer receives solar insolation as shown in Fig. 1b. Therefore, the heat transferred thorough the liquid is lower than through the solid and continuously dropping as the absorber surface cools down (first) towards the melting temperature of silicon, which causes the interface to move towards the absorber surface (Fig. 1). From Eq. (1), the energy balance across the moving solid/liquid interface gives

$-\left.k_{l} \frac{d T}{d x}\right|_{x=X_{m}^{-}}+\left.k_{s} \frac{d T}{d x}\right|_{x=X_{m}^{+}}=\rho_{l} L_{f} \frac{d X_{m}}{d t}$

where $X_{m}$ is the location of the melting interface (see Fig. 1), $k_{s}$ and $k_{l}$ are the thermal conductivities of the solid and liquid respectively, $\rho_{l}$ is the density of the liquid and $L_{f}$ is the latent heat of fusion of silicon. Eq. (4) balances heat conduction from the liquid side to the solid side at the interface, along with the energy released from solidification via the latent heat of fusion. While the absorber surface is set to be adiabatic for the night time ( $Q_{i n}=0$, see Fig. 1), a heat flux is still driven from the absorber to the interface by virtue of the temperature difference that exists at the onset of night time operations. The energy emitted out of the PCM tank by the emitter over a small time interval $\Delta t$ is $\dot{Q}_{e}^{\prime \prime} \times A_{e} \times \Delta t$. The total energy remaining in the system is the total energy at the previous time minus the emitted energy. This can be expressed mathematically as

$E_{\text {tot }}(t+\Delta t)=E_{\text {tot }}(t)-\dot{Q}_{e}^{\prime \prime}(t) \times A_{e} \times \Delta t$

The total energy of the PCM tank at any given time (and interface location) comprising of a liquid and solid portion can be expressed as

$$
\begin{aligned}
E_{\text {tot }}(t)= & \int_{X_{m}(t)}^{L}\left(\rho_{s} C_{p, s} T_{s}(x) A(x)\right) d x \\
& +\int_{0}^{X_{m}(t)}\left(\rho_{l} C_{p, l} T_{l}(x) A(x)\right) d x \\
& +\int_{0}^{X_{m}(t)}\left(\rho_{l} A(x) L_{f}\right) d x
\end{aligned}
$$

where $L_{f}$ is the latent heat of fusion of silicon. Note that Eq. (6) implicitly assumes that temperatures and interface location vary with time and hence total energy of the PCM varies with time. The first two terms in Eq. (6) are the temperature based sensible enthalpy of the solid and liquid respectively, while the last term is the heat stored in the latent heat of fusion of silicon. At each new time-step the interface location $X_{m}$, emitter temperature $T_{e}$ (and emitter heat flux $\dot{Q}_{e}^{\prime \prime}$ ) and absorber temperature $T_{a}$ (and absorber heat flux $\dot{Q}_{\alpha}^{\prime \prime}$ ) are unknown. In order to solve this system, Eq. (4) is discretised using a forward difference in time.

$\rho_{l} L_{f} A(x) \frac{\left(X_{m}(t+\Delta t)-X_{m}(t)\right)}{\Delta t}=\dot{Q}_{a}^{\prime \prime}(t)-T R \times \dot{Q}_{e}^{\prime \prime}(t)$

Integrating Eq. (1) after separating variables gives the temperature in the solid and liquid as a function of the coordinate $x$ and thermal properties.

$$
\begin{aligned}
& T_{l, s}(x)= T_{m} \\
&-\frac{L \dot{Q}_{\text {eff }}^{\prime \prime}}{(\sqrt{T R}-1)^{2}}\left(\frac{1}{\frac{X_{m}}{L}+\frac{1}{(\sqrt{T R}-1)}}-\frac{1}{\frac{x}{L}+\frac{1}{(\sqrt{T R}-1)}}\right) \\
& \dot{Q}_{\text {eff }}^{\prime \prime}= \begin{cases}\frac{\dot{Q}_{a}^{\prime \prime}}{k_{l}} & \text { Liquid } \\
\frac{\dot{Q}_{e}^{\prime \prime} \times T R}{k_{s}}, & \text { Solid }\end{cases}
\end{aligned}
$$

where $T_{m}$ is silicon's melting temperature $(=1680 \mathrm{~K})$. Setting $x=L$ in Eq. (8) and choosing the solid case for $\dot{Q}_{\text {eff }}^{\prime \prime}$ gives $T_{e}$.

$T_{e}=T_{m}-\frac{L \times T R \times \dot{Q}_{e}^{\prime \prime}}{k_{s} \times(\sqrt{T R}-1)^{2}}\left(\frac{1}{\frac{X_{m}}{L}+\frac{1}{(\sqrt{T R}-1)}}-\frac{1}{1+\frac{1}{(\sqrt{T R}-1)}}\right)$

which is valid for every $T_{e} \leqslant T_{m}$. As done (Datas et al, 2013) the emitter is assumed to be a black body emitting onto ideal PV cells (in which only radiative recombination is taking place). Therefore, the flux out of the emitter can be expressed as a function of the emitter temperature $\left(T_{e}\right)$ (Datas and Algora, 2010; Datas et al., 2013)

$$
\begin{gathered}
\dot{Q}_{e}^{\prime \prime} / \pi=F_{e c} \dot{E}\left(\varepsilon_{G}, \infty, 300, q V\right)-\dot{E}\left(0, \infty, T_{e}, 0\right) \\
+\frac{A_{e}}{A_{c}} \cdot \frac{\rho_{B S R} F_{e c}^{2}}{1-\rho_{B S R} F_{c c}^{(e)}} \dot{E}\left(0, \varepsilon_{G}, T_{e}, 0\right) \\
\dot{E}\left(\varepsilon_{1}, \varepsilon_{2}, T, \mu\right)=\frac{2}{h^{3} c^{2}} \int_{\varepsilon_{1}}^{\varepsilon_{2}} \frac{\varepsilon^{3}}{\exp [(\varepsilon-\mu) / k T]-1} d \varepsilon
\end{gathered}
$$

where $F_{e c}$ and $F_{c c}^{(e)}$ are the emitter-cells and cells-cells view factors, respectively, $\varepsilon_{G}$ and $V$ are the PV cell's band-gap energy and voltage, respectively (both optimised in the steady state (Datas et al., 2013), $A_{c}$ is the cell's area, $\rho_{B S R}$ is the BSR reflectivity and $\dot{E}\left(\varepsilon_{1}, \varepsilon_{2}, T, \mu\right)$ is the radiative energy flux emitted by a surface at temperature $T$ and with chemical potential $\mu$ in vacuum, in the spectral interval $\left(\varepsilon_{1}, \varepsilon_{2}\right)$, in the normal direction and per unit of solid angle.

The final electrical power density (in watts per unit cell area) is obtained from Datas and Algora (2010) and Datas et al. (2013):

$$
\begin{gathered}
P_{d}=J V=q \pi V\left\{\begin{array}{l}
\frac{A_{e}}{A_{e}} F_{e c} \dot{N}\left(\varepsilon_{G}, \infty, T_{e}, 0\right) \\
-\left(1-F_{c c}^{(e)}\right) \dot{N}\left(\varepsilon_{G}, \infty, 300, q V\right) \\
-n_{\text {int }}^{2}\left(1-\rho_{B S R}\right) \dot{N}\left(\varepsilon_{G}, \infty, 300, q V\right)
\end{array}\right\} \\
\dot{N}\left(\varepsilon_{1}, \varepsilon_{2}, T, \mu\right)=\frac{2}{h^{3} c^{2}} \int_{\varepsilon_{1}}^{\varepsilon_{2}} \frac{\varepsilon^{2}}{\exp [(\varepsilon-\mu) / k T]-1} d \varepsilon
\end{gathered}
$$


where $\dot{N}\left(\varepsilon_{1}, \varepsilon_{2}, T, \mu\right)$ has the same meaning than $\dot{E}\left(\varepsilon_{1}, \varepsilon_{2}\right.$, $T, \mu)$ but for the photon flux instead of the energy flux.

The entire system at the new time-step is calculated by simultaneously solving Eqs. (5), (7), (10) and (11). This ensures that energy is balanced as time marching progresses. During this process, the PV cell's voltage $(V)$ is optimised to find the maximum power point (MPP) of the $J-V$ curve at each time.

The PCM tank is considered discharged when $X_{m}=0$, i.e. fully solidified. The thermal properties of silicon used for the numerical solution are tabulated below. The thermal conductivity of silicon has a sharp transition around its melting point with solid and liquid phases having distinctly different thermal conductivities. Apart from this, the other thermal properties vary smoothly with temperature. For this study, we have used values corresponding to those at silicon's melting point (Nakamura and Hibiya, 1992) as shown in Table 2.

\subsection{Computational fuid dynamics model: meltFoam}

The CFD model was created in the OpenFOAM Toolbox, and utilises the meltFoam solver developed for latent heat thermal energy storage modelling purposes (Rösler and Brüggemann, 2011). The governing equations are described in Rösler and Brüggemann (2011), and are not repeated here. MeltFoam is based on the Enthalpy-Porosity method (Brent et al., 1988). Modelling the phase change using the basic enthalpy method involves assigning nodal latent heat values according to the temperature of each cell. As a cell changes from to liquid to solid, its velocity must be set to zero (Brent et al., 1988). This can be achieved by increasing the viscosity of cells as the latent heat decreases (Gartling, 1978). An alternative to this proposed by Brent et al. (1988) models cells undergoing a phase change as pseudo-porous material. Named the EnthalpyPorosity method, the porosity of a cell is a function of latent heat which ranges from one (liquid) to zero (solid). For example, during solidification when the value of the latent heat in the cell reaches the value of the latent heat of fusion, the porosity of the cell reaches zero, hence the cell is fully solid. Brent et al. (1988) noted that while any convenient method for extinguishing the velocities in solidifying cells could be used, methods which employ a smooth transition will provide easier convergence of the numerical solution. Rösler and Brüggemann (2011) provided this

Table 2

Silicon thermal properties.

\begin{tabular}{lll}
\hline Property & Solid & Liquid \\
\hline Heat capacity $\left(C_{p}\right)$ & $1040 \mathrm{~J} / \mathrm{kg} \mathrm{K}$ & \\
Thermal conductivity $(k)$ & $20 \mathrm{~W} / \mathrm{m} \mathrm{K}$ & $60 \mathrm{~W} / \mathrm{m} \mathrm{K}$ \\
Density $(\rho)$ & $2520 \mathrm{~kg} / \mathrm{m}^{3}$ & \\
Latent heat of fusion $\left(L_{f}\right)$ & $1800 \mathrm{~kJ} / \mathrm{kg}$ & \\
Melting point $\left(T_{m}\right)$ & $1680 \mathrm{~K}$ & \\
Volumetric thermal expansion $(\beta)$ & - & $1.43 \times 10^{-4}(1 / \mathrm{K})$ \\
Laminar viscosity $\left(\mu_{L}\right)$ & - & $2.97 \times 10^{-7}\left(\mathrm{~m}^{2} / \mathrm{s}\right)$ \\
\hline
\end{tabular}

continuous liquid fraction by using an error function. The model also considers the effects of natural convection within the liquid part using the Boussinesq approximation. The accuracy of the meltFoam solver has been previously validated by comparison with the experimental results of Gau and Viskanta (1984).

The top surface and the side surfaces have an adiabatic boundary condition. In order to set the boundary condition of the emitter (bottom surface) heat flux (Eq. (11)), the swak4foam library (Gschnaider, 2012) was used to set temperature dependent heat fluxes. The meltFoam code was tested for grid convergence and minimum time step $(\Delta t)$ required for the results to be invariant with both grid and time step refinements. Fig. 2 shows the results of these two studies. A grid of $11 \times 11 \times 36$ (with absorber area of $10 \mathrm{~cm} \times 10 \mathrm{~cm}$, length of $10 \mathrm{~cm}$ ) and time step of $0.05 \mathrm{~s}$ are required for the results to be invariant and these values have been adopted for this work. Fig. 3 shows the grid used for the three dimensional PCM tank along with temperature $(T)$ and porosity $(\alpha)$ at $t=30 \mathrm{~min}$ for geometric and initial conditions corresponding to row 1 of Table 1 , where $\alpha$ is the dimensionless liquid fraction. The part of the PCM tank where $\alpha$ equals one is completely liquid and where $\alpha$ equals zero is completely solid.

\section{Results}

\subsection{Computational model results}

The meltFoam model described in section two was run for conditions described in Table 1 rows $1-3$. The natural convection model in the solver was left on for these simulations to ascertain the effect of natural convection in the liquid phase for the vertical tank orientation chosen in the analytical model (where natural convection was ignored). These simulations took anywhere from a few hours to few days depending on the choice of parameters on a standard desktop PC with an Intel ${ }^{\circledR}$ Core $^{\mathrm{TM}}$ i7-3770 CPU (3.4 GHz) processor with 8 GB RAM. Fig. 4 shows the time evolution of temperature and alpha for the case corresponding to row 1 of Table 1. As can be seen from this figure and Fig. 3, the temperature and alpha profiles are fairly one dimensional for entire solidification cycle. The CFD results obtained in these runs are used in Section 3.2 to verify the assumptions made in the semi-analytical model.

\subsection{Effect of $A R$, TR at fixed $L$ (verification against $C F D$ )}

Like with the meltFoam solver, the sensitivity of the time marching method to choice of $\Delta t$ was explored for the semianalytical model for the case of $A R=10, T R=0.45$ and $L=10 \mathrm{~cm}$ (row 1, from Table 1). It was found that for up to $\Delta t=60 \mathrm{~s}(1 \mathrm{~min})$ there is no difference in the night time performance calculated. Some small discrepancy exists in the temperature, $X_{m} / L$ and power profiles for $\Delta t$ larger than this value. Therefore, conservatively all simulations were 

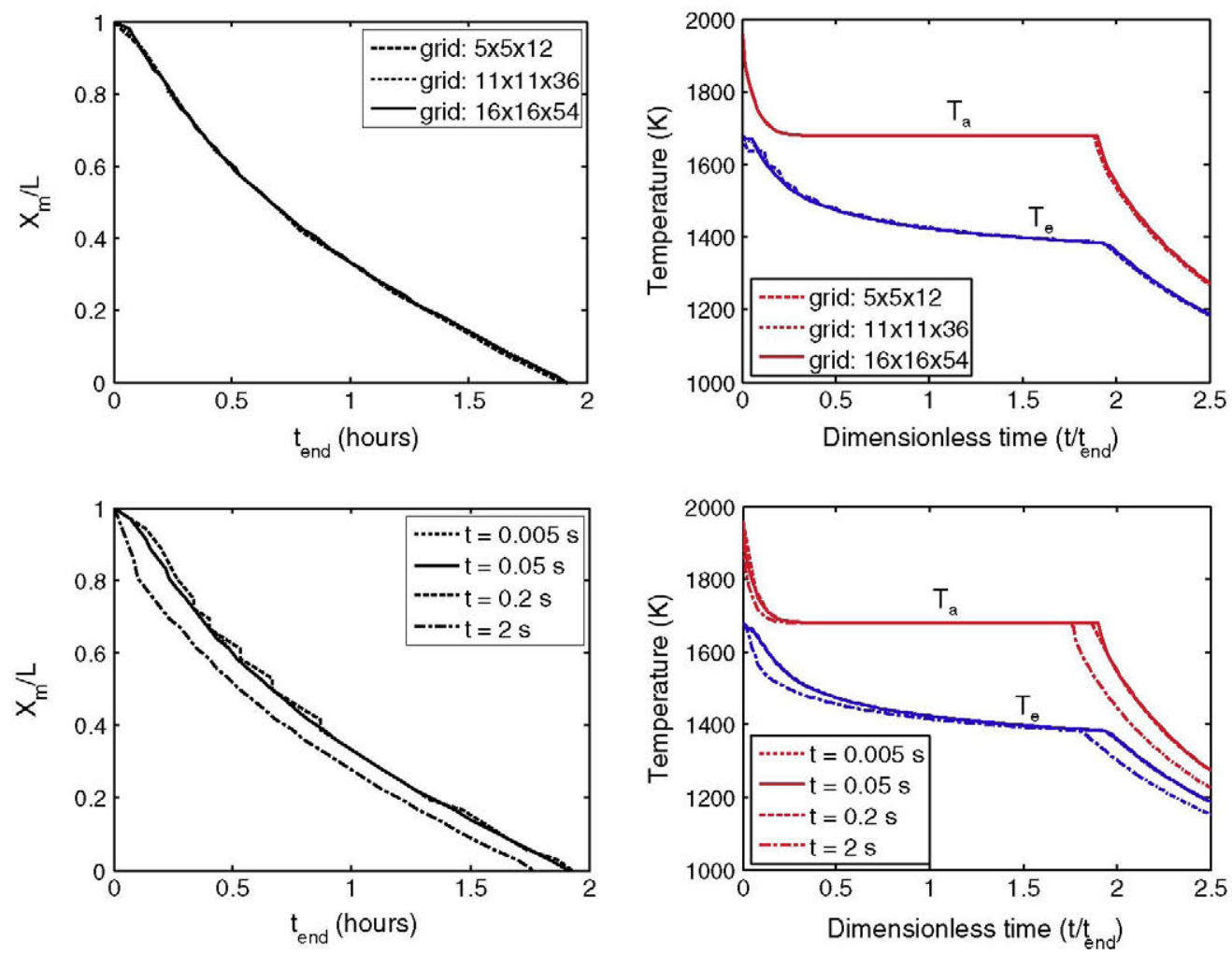

Fig. 2. Grid and time convergence for meltFoam CFD results.
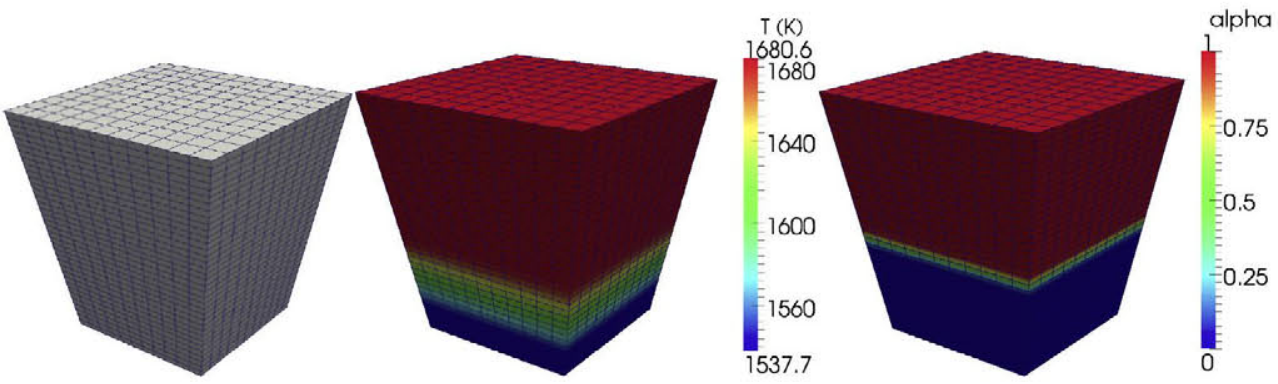

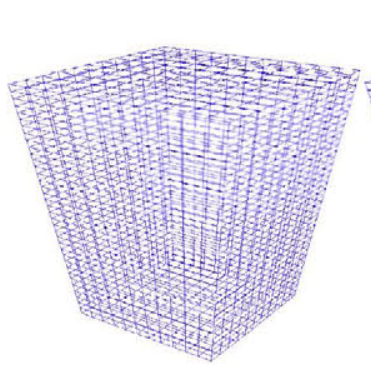

(a)

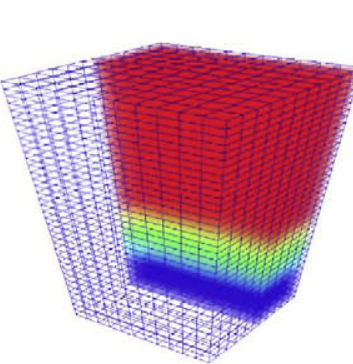

(b)

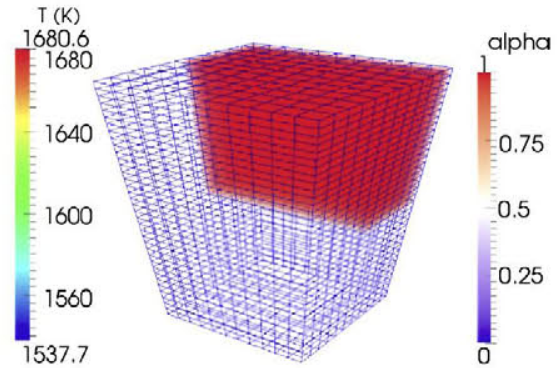

(c)

Fig. 3. (a) Grid used in meltFoam model, (b) temperature (K) and (c) liquid fraction (alpha) for row 1 from Table 1 at $t=30 \mathrm{~min}$.

performed with $\Delta t=45 \mathrm{~s}$ to maintain accuracy. The accuracy of the assumptions made in the semi-analytical model developed in Section 2.2 is verified by comparison with independently obtained CFD (meltFoam) solver results (given in Section 2.3). Fig. 5 shows the night time performance for a PCM tank of a fixed length of $10 \mathrm{~cm}$ for three different $A R$ and corresponding $T R$ choices (rows 1-3 from Table 1). For the steady state, day time analysis the parameter $A R$ was varied as it is one of the key geometric parameters. The choices of $T R$ listed in Table 1 reflect the values required (at those $A R s$ ) to fully melt the tank. It is equally possible to fix the $T R$ to a given value and ascertain the 

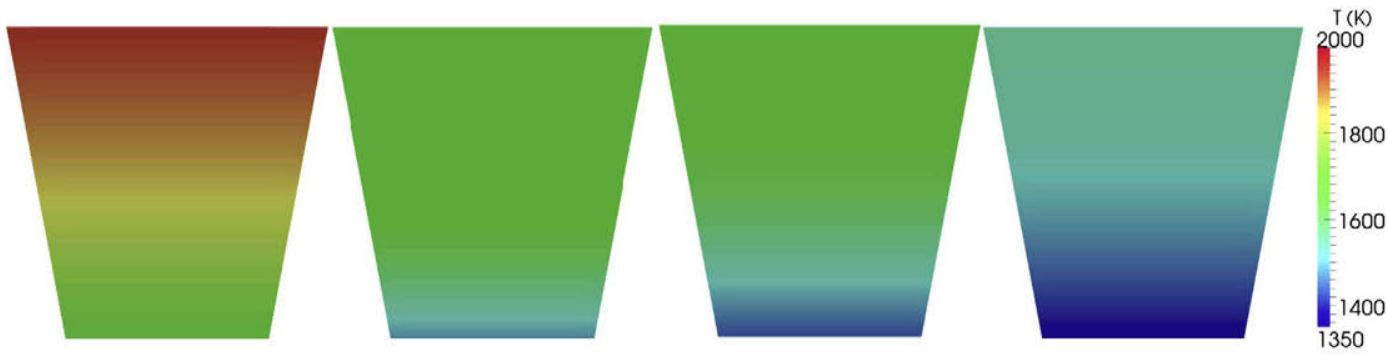

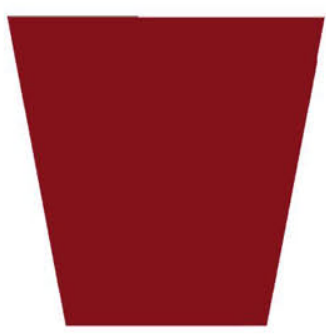

(a)

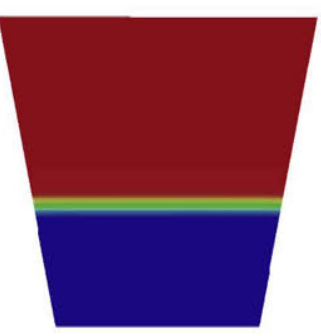

(b)

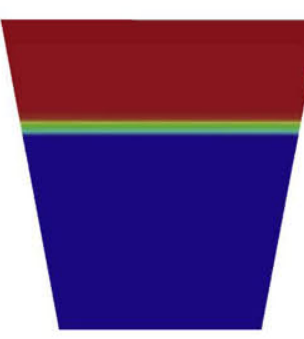

(c)

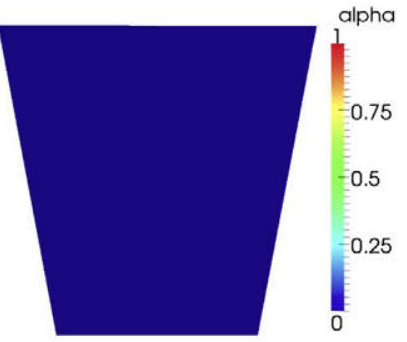

(d)

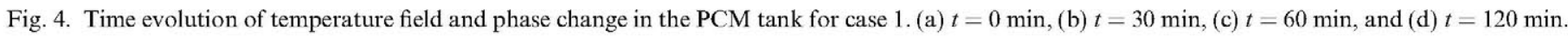
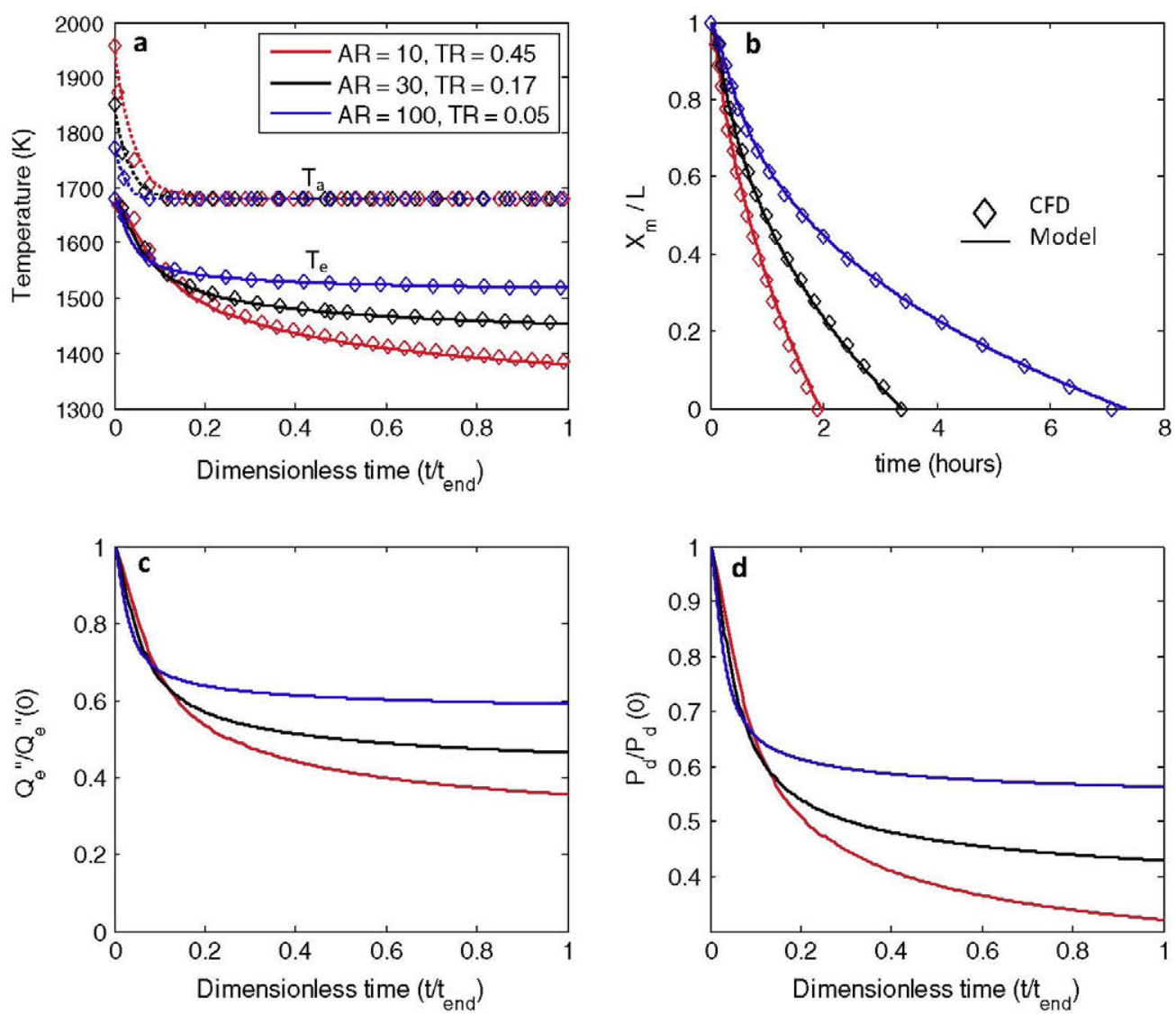

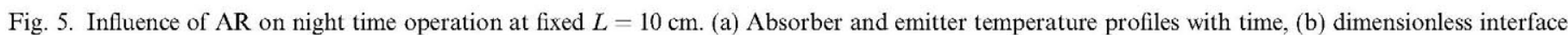
location $\left(X_{m} / L\right)$ with time, (c) dimensionless emitter power per unit area and (d) dimensionless PV power generated per unit area.

$A R$ value required to fully melt the PCM tank. In this work, we continue to compare the results with the same choices of $A R$ made in Datas et al. (2013). The profiles are plotted on a dimensionless time scale (normalised by end time for each case) for three of the plots ( $a, c$ and d) for easy comparison. The comparison with the CFD solver is quite good as seen from the absorber, emitter temperature profiles in Fig. 5a and $X_{m} / L$ (dimensionless melting line location) in Fig. $5 \mathrm{~b}$ 

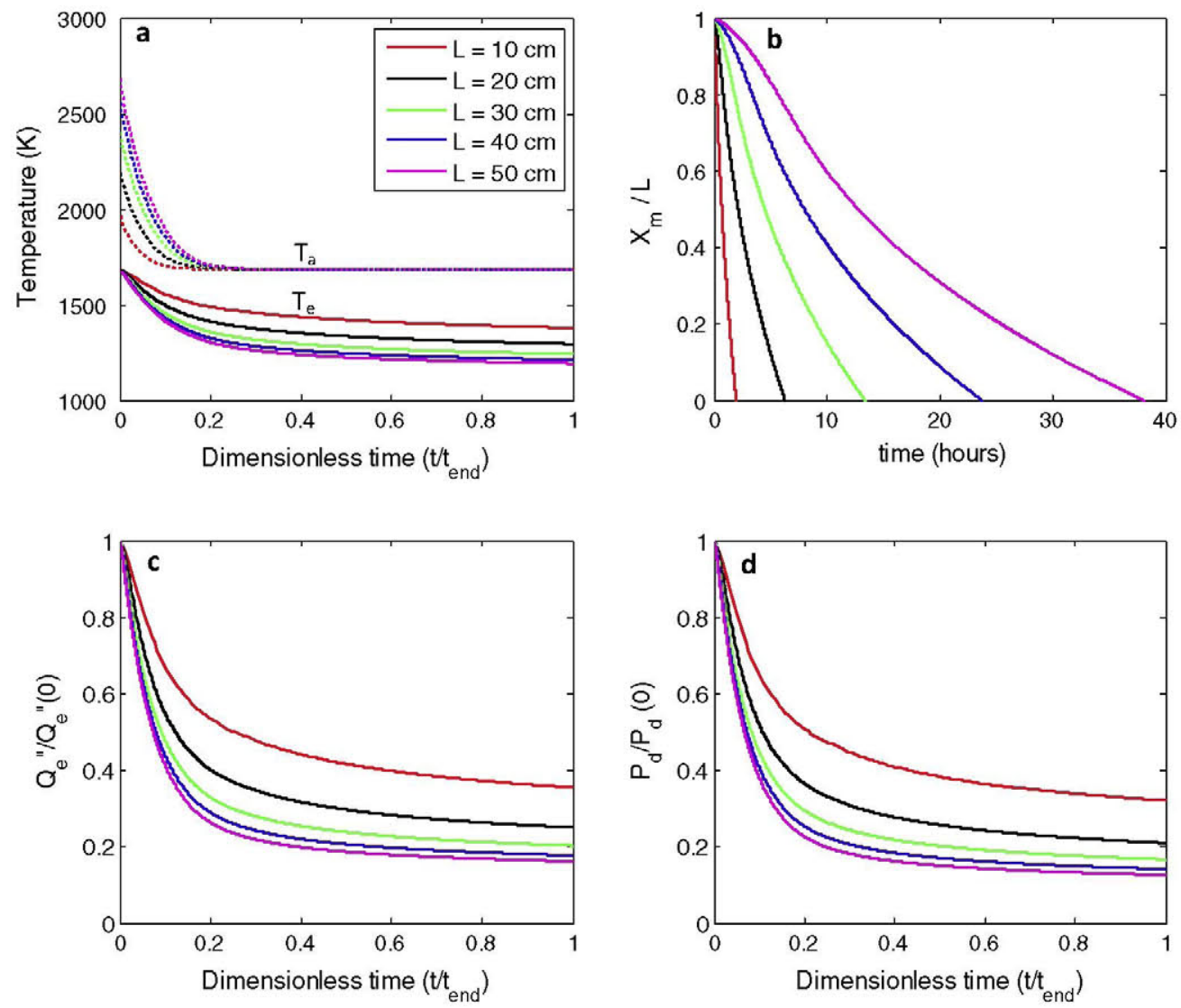

Fig. 6. Influence of PCM tank length on night time operation at fixed $A R=10$. (a) Absorber and emitter temperature profiles with time, (b) dimensionless interface location $\left(X_{m} / L\right)$ with time, (c) dimensionless emitter power per unit area and (d) dimensionless PV power generated per unit area.

where the diamond symbols are CFD solver results and lines are the semi-analytical model results. The average error in comparison to meltFoam CFD results in $X_{m} / L$ was less than $1.5 \%$ and in absorber/emitter temperatures is less than $1 \%$. This verifies that the quasi-steady and quasi-stationary assumptions employed in the semi-analytical model along with the zero natural convection effects (which was left turned on in the CFD solver) are accurate. The influence of natural convection is negligible owing to the orientation chosen in which buoyancy cannot drive convective currents through the liquid silicon. At the present time, it is not possible to provide experimental validation as no data currently exists for this particular application of the SISTPV system.

At the start of the night time operation, the absorber temperature drops from the initial value to the melting point of silicon. This happens because there is no input energy in the absorber side. Therefore, the entire liquid phase drives towards a thermal equilibrium to reach the melting temperature with no thermal gradient in the liquid. This is attained after a short but finite time. However, owing to the differences in $A R$ and $T R$, the corresponding emitter temperatures are quite different. $A R=100$ has the highest emitter temperature of over $1500 \mathrm{~K}$, while $A R=10$ has the least emitter temperature of under $1400 \mathrm{~K}$. While this is not a large difference in temperature, it is sufficient to cause the emitted power fraction
$\left(\dot{Q}_{e}^{\prime \prime} / \dot{Q}_{e}^{\prime \prime}(0)\right)$ to be significantly different between the three cases (Fig. 5c) with the $A R=100, T R=0.05$ case having the highest fraction of around 0.6 and $A R=10$, $T R=0.45$ having the least. The corresponding total time $\left(t_{\text {end }}\right)$ before the PCM tank is fully solidified is shown in Fig. 5b. The $A R=100, T R=0.05$ case has the longest discharge time of over $7 \mathrm{~h}$, while $A R=10, T R=0.45$ only offers around $2 \mathrm{~h}$. The cell power density $P_{d}$ is the power produced at the PV cells per unit area. The corresponding cell power density fraction $\left(P_{d} / P_{d}(0)\right)$ also shows that the $A R=100, \quad T R=0.05$ case offers the best power conversion.

\subsection{Effect of $L$ at fixed $A R, T R$}

The influence of different PCM lengths are explored below for the same three $A R$ cases explored in Section 3.1.

\subsection{1. $A R=10, T R=0.45$}

The temperature profiles in Fig. 6a demonstrate that $L=10 \mathrm{~cm}$ has the highest emitter temperature with the absorber reaching the melting point temperature the quickest. This is to be expected as for shorter lengths the thermal resistance to heat conduction will be the least. Length also has a stronger influence on discharge time than $A R$ as seen from Fig. 6b with $L=50 \mathrm{~cm}$ provides storage of nearly $40 \mathrm{~h}$ ( $\sim 2$ days). The emitted power and cell power densities 
follow similar trends, with $L=10 \mathrm{~cm}$ offering the highest fractions and $L=50 \mathrm{~cm}$ offering the least. However, since the discharge time is very short (around $2 \mathrm{~h}$ ) for $L=10 \mathrm{~cm}$, its higher cell power density should be weighed against reduced discharge time. This suggests that the design can be chosen to either provide longer duration of storage or higher average power.

\subsection{2. $A R=30, T R=0.17$}

The general trends for $A R=30$ for the different lengths of PCM are the same as the case of $A R=10$ as seen in Fig. 7. However, the discharge time increases for all of the length choices. For example, $L=20 \mathrm{~cm}$ gives around $10 \mathrm{~h}$ of storage which might be adequate for night time operation. However, this also needs to be weighed against the efficiency during the day time (steady state) operation indicated in Table 1.

\subsection{3. $A R=100, T R=0.05$}

Fig. 8 shows that $A R=100, T R=0.05$ case has the highest emitter temperature (after the liquid portion equilibrates to the melting temperature $T_{m}$ ) of all of the three $A R$ options investigated. The corresponding cell power density fraction is also the highest. This difference in night time performance arises primarily from the fact that the steady state operation had the least temperature difference between the emitter temperature and absorber temperatures for
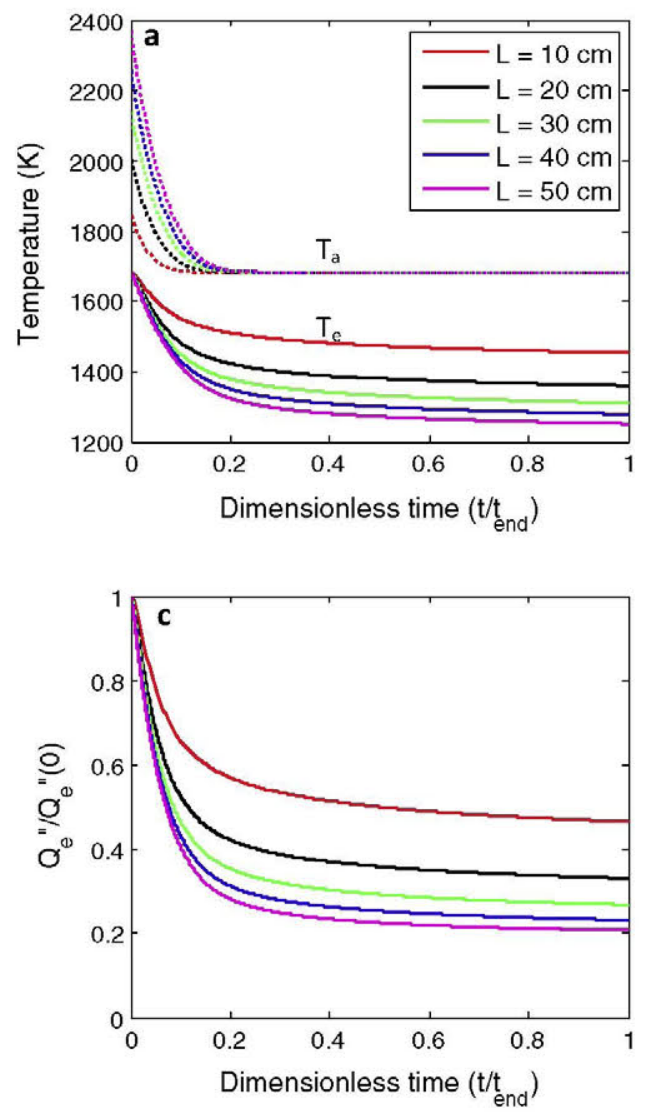

$A R=100$ (seen at $t=0$ ) and progressively higher $\Delta T$ for lower $A R s$. Having a lower absorber temperature difference and yet having the full PCM melted is beneficial to keeping the emitter temperature fairly high during the discharge phase as the interface moves very slowly owing to the low temperature differences, which leads to a higher emitted and hence converted cell power.

\subsection{Overall performance metrics}

The time dependent profiles shown in Sections 3.1 and 3.2 can be used to further calculate the overall night time performance by integrating them over the discharge time. The main metrics for overall night time performance are the final emitter temperature $\left(T_{e, e n d}\right)$, storage time $\left(t_{\text {end }}\right)$, total energy delivered per unit hole area $\left(E_{\text {tot }} / A_{h}\right)$, average converted power per unit hole area $\left(P_{\text {avg }} / A_{h}\right)$ and total nigh time system efficiency $\left(\eta_{t o t}\right)$. In order to make consistent comparisons, the inlet (hole) area is fixed between the different configurations. For the steady state day time operation, different PCM tank geometries can only be compared when the input solar energy into the PCM tank is the same during daytime operations for all of the options considered. Fixing solar concentration $(C)$ and inlet hole area $\left(A_{h}\right)$ fixes the total solar energy input to the system for all of the cases studied. Since the starting point of the night time analysis is the daytime steady state values from Table 1, we will
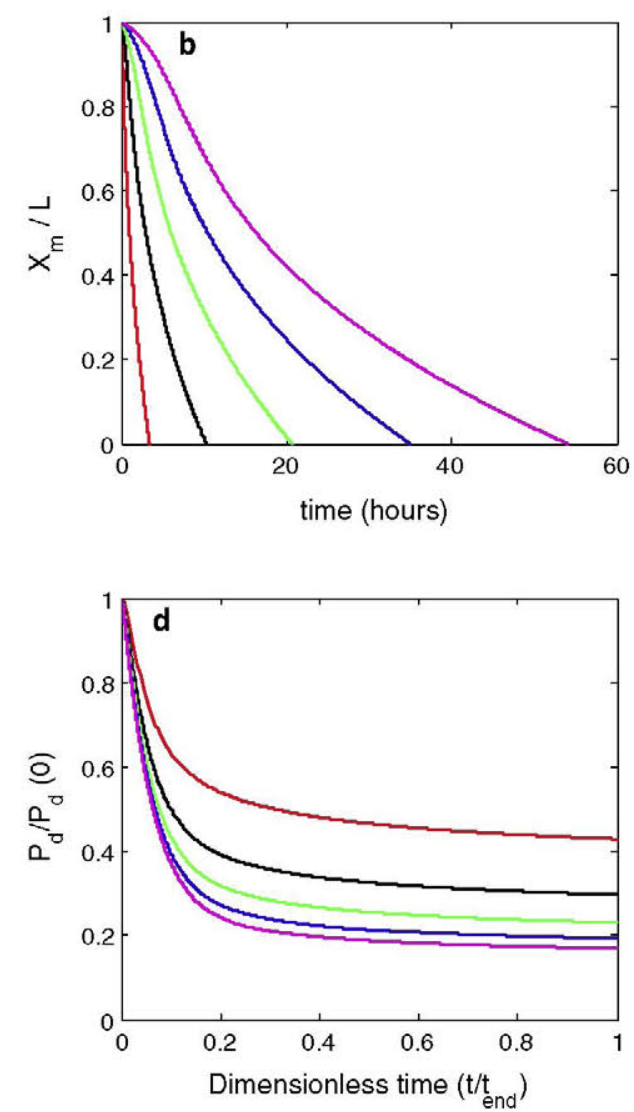

Fig. 7. Influence of PCM tank length on night time operation at fixed $A R=30$. (a) Absorber and emitter temperature profiles with time, (b) dimensionless interface location $\left(X_{m} / L\right)$ with time, (c) dimensionless emitter power per unit area and (d) dimensionless PV power generated per unit area. 

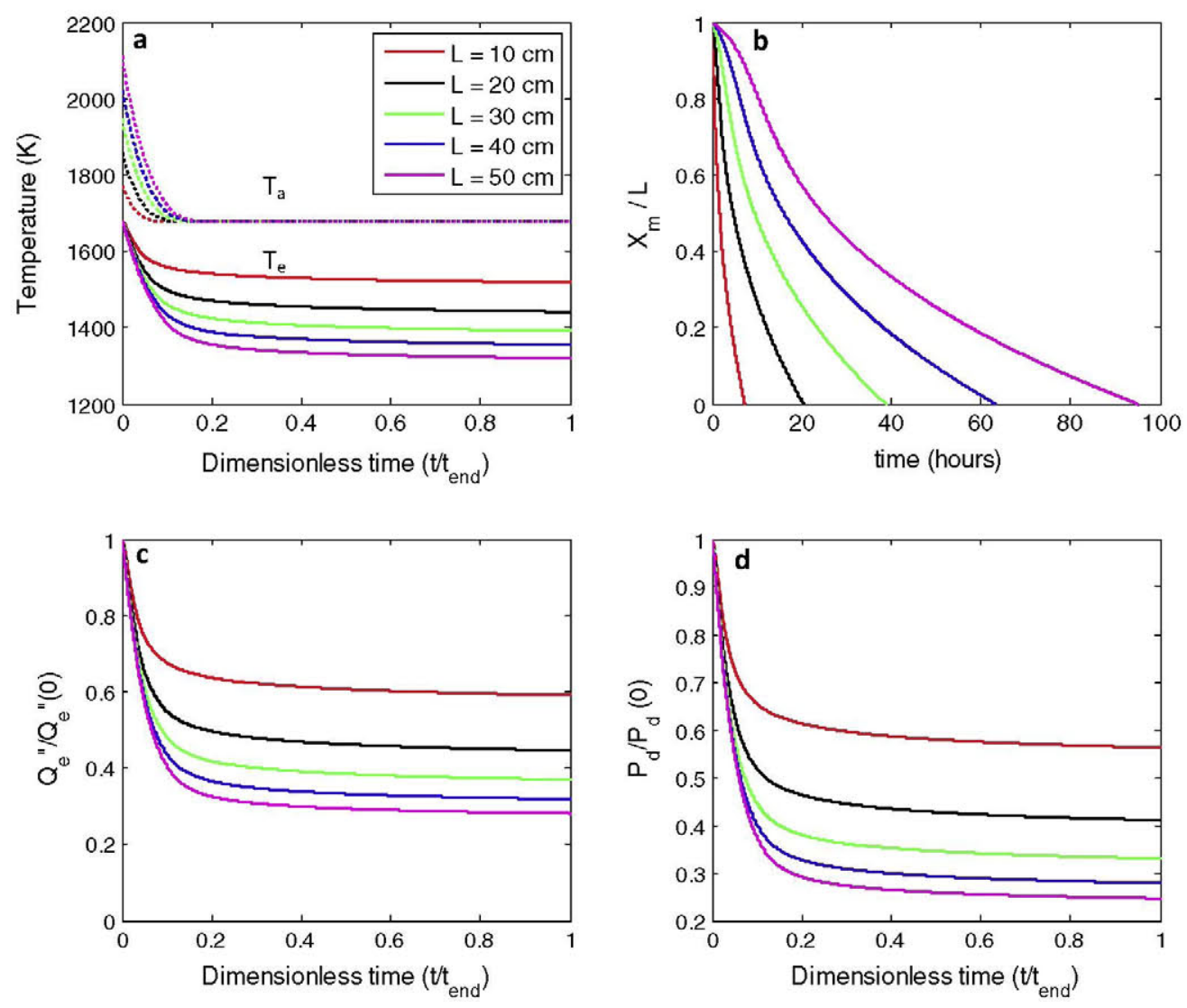

Fig. 8. Influence of PCM tank length on night time operation at fixed $A R=100$. (a) Absorber and emitter temperature profiles with time, (b) dimensionless interface location $\left(X_{m} / L\right)$ with time, (c) dimensionless emitter power per unit area and (d) dimensionless PV power generated per unit area.

assume a common $A_{h}$ for the night time comparisons as well to keep it consistent with the daytime analysis. Using this, the total converted energy $\left(E_{t o t}\right)$ per unit $A_{h}, P_{\text {avg }}$ and $\eta_{\text {tot }}$ are defined as

$E_{\text {tot }} / A_{h}=\int_{0}^{t_{e n d}} \frac{P_{d}(t) \times A_{c}}{A_{h}} d t=A R \times T R \times F_{e c} \times \int_{0}^{t_{e n d}} P_{d}(t) d t$

$P_{\text {avg }} / A_{h}=\frac{E_{\text {tot }} / A_{h}}{t_{\text {end }}}$

$$
\eta_{\text {tot }}=\frac{P_{\text {tot }}}{Q_{e, t o t}}=\frac{\int_{0}^{t_{\text {end }}} P_{d}(t) \times A_{c} d t}{\int_{0}^{t_{\text {end }}} \dot{Q}_{e}^{\prime \prime}(t) \times A_{e} d t}=F_{e c} \frac{\int_{t_{e}}^{t_{\text {end }}} P_{d}(t) d t}{\int_{0}^{t_{\text {end }}} \dot{Q}_{e}^{\prime \prime}(t) d t}
$$

where the view factor $F_{e c}$ is equal to the emitter to PV cell area ratio $\left(A_{c} / A_{e}\right)$ and its value is 0.95 as in the previous work (Datas et al., 2013).

Table 3 shows, the values of $T_{e, \text { end }}, t_{\text {end }}, E_{\text {tot }} / A_{h}$ and $P_{\text {avg }}$ for the different configurations studied here. The main metrics are the average emitted power and total time. The ideal combination for the best suited SISTPV system

Table 3

Night time overall performance metrics for $T_{e, \text { init }}=T_{m}=1680 \mathrm{~K}$.

\begin{tabular}{|c|c|c|c|c|c|c|c|}
\hline$L(\mathrm{~cm})$ & $A R(-)$ & $T R(-)$ & $T_{e, \text { end }}(\mathrm{K})$ & $t_{\text {end }}(\mathrm{hrs})$ & $E_{t o t} / A_{h}\left(\mathrm{MJ} / \mathrm{cm}^{2}\right)$ & $P_{a v g} / A_{h}\left(\mathrm{~W} / \mathrm{cm}^{2}\right)$ & $\eta_{T P V, t o t}(-)$ \\
\hline 10 & 10 & 0.45 & 1380 & 2.0 & 0.15 & 20.72 & 0.39 \\
\hline 10 & 30 & 0.17 & 1454 & 3.4 & 0.31 & 25.26 & 0.39 \\
\hline 10 & 100 & 0.05 & 1518 & 7.3 & 0.82 & 30.86 & 0.40 \\
\hline 20 & 10 & 0.40 & 1296 & 6.3 & 0.29 & 12.91 & 0.37 \\
\hline 20 & 30 & 0.14 & 1359 & 10.3 & 0.63 & 16.98 & 0.38 \\
\hline 20 & 100 & 0.05 & 1442 & 20.3 & 1.65 & 22.57 & 0.39 \\
\hline 30 & 10 & 0.32 & 1243 & 13.4 & 0.43 & 8.89 & 0.37 \\
\hline 30 & 30 & 0.13 & 1310 & 20.7 & 0.96 & 12.84 & 0.37 \\
\hline 30 & 100 & 0.05 & 1392 & 38.9 & 2.51 & 17.91 & 0.38 \\
\hline 40 & 10 & 0.27 & 1214 & 23.8 & 0.56 & 6.55 & 0.36 \\
\hline 40 & 30 & 0.13 & 1278 & 35.0 & 1.28 & 10.19 & 0.36 \\
\hline 40 & 100 & 0.04 & 1354 & 63.3 & 3.40 & 14.91 & 0.37 \\
\hline 50 & 10 & 0.22 & 1195 & 38.1 & 0.69 & 5.00 & 0.36 \\
\hline 50 & 30 & 0.11 & 1251 & 54.1 & 1.62 & 8.32 & 0.36 \\
\hline 50 & 100 & 0.04 & 1319 & 95.0 & 4.36 & 12.74 & 0.37 \\
\hline
\end{tabular}


would have high $P_{a v g}$ and high $t_{\text {end }}$ (i.e. high $E_{t o t} / A_{h}$ ), providing sufficient power over a long enough time. From Table 3 , it is seen that the cases with low $T R(0.05)$ and high $A R(100)$ have the best combination of $P_{\text {avg }}$ and $t_{\text {end }}$. Under this condition, $P_{\text {avg }} / A_{h}$ is nearly $60 \%$ of the steady state power density. Correspondingly, the $T_{e, \text { end }}$ is also high for this combination of $T R$ and $A R$. The cases with large $L(40-50 \mathrm{~cm})$ are capable of providing long discharge time (even a few days). However, the average power is lower. On the contrary, small $L(10-20 \mathrm{~cm})$ are capable of providing very high power density but at the expense of shorter running times. Therefore, there exists a trade-off in the system design that must be solved taking into account the specific requirements of each project and the climate conditions at the specific system location. The system design will depend on the desired hours of operation for night time, once the desired duration is determined and structurally practical $A R$ and $T R$ are set, the model can be used to determine the length of the storage tank required to deliver this storage. Alternatively, the system can also be designed for a desired average power or a combination thereof of average power and discharge time.

\section{Conclusions}

The transient model developed using a time marching scheme based on the balanced enthalpy method allowed us to analyse the night time operation of the SISTPV system proposed in previous work. This model was verified against an independent CFD solver meltFoam running on the OpenFOAM platform. The model showed that the combination of low tapering ratio $(T R=0.05)$ and large inlet hole-to-absorber area ratio $(A R=100)$ is the best option for maximising both the average power converted and discharge time. Average night time power densities per unit hole area of up to $30.86 \mathrm{~W} / \mathrm{m}^{2}$ were calculated for a $10 \mathrm{~cm}$ long tank with $A R=100, T R=0.05$ with a night time storage of $7.3 \mathrm{~h}$. Longer tanks allowed for more storage (a few days) but have the disadvantage of lower average power output. The work presented in this paper clearly highlights the need for a thorough heat transfer design in the PCM tank that allows for the lowest temperature difference between the absorber and emitter, which results in very good day and night operations. Silicon is an excellent choice of PCM material owing to its high latent heat of fusion. This is seen from the very long discharge times (several hours) calculated for compact PCM tanks. Further improvements need to be made to the heat transfer modelling, such as including heat losses from the side wall, in order for the model to be more accurate in making quantitative predictions particularly for small values of TR. Future work will also focus on using the CFD model to study the effects of natural convection in the liquid layer in tank orientations that will allow for it to play a role in the heat transfer. In addition, the properties of actual emitter and PV cell materials should be included.

\section{Acknowledgements}

The authors thank Dr. Donald L. Chubb of NASA Glenn Research Center, for insightful discussions and comments.

\section{References}

Alexiades, V., Solomon, A.D., 1993. Mathematical Modeling of Melting and Freezing Processes. CRC Press.

Araújo, G.L., Martí, A., 1994. Absolute limiting efficiencies for photovoltaic energy conversion. Sol. Energy Mater. Sol. Cells 33, 213-240.

Bauer, T., 2011. Thermophotovoltaics: Basic Principles and Critical Aspects of System Design. Springer, Berlin, Heidelberg.

Brent, A., Voller, V., Reid, K.T.J., 1988. Enthalpy-porosity technique for modeling convection-diffusion phase change: application to the melting of a pure metal. Numer. Heat Transfer, Part A Appl. 13, 297-318.

Catalano, A., 1996. Thermophotovoltaics: a new paradigm for power generation? Renew. Energy 8, 495-499.

Chubb, D., 2007. Fundamentals of Thermophotovoltaic Energy Conversion. Elsevier Science.

Chubb, D.L., Good, B.S., Lowe, R.A., 1996. Solar thermophotovoltaic (STPV) system with thermal energy storage. AIP Conf. Proc. 358, 181198.

Datas, A., Algora, C., 2010. Detailed balance analysis of solar thermophotovoltaic systems made up of single junction photovoltaic cells and broadband thermal emitters. Sol. Energy Mater. Sol. Cells 94, 2137 2147.

Datas, A., Algora, C., 2012. Global optimization of solar thermophotovoltaic systems. Prog. Photovoltaics: Res. Appl., 1040-1055.

Datas, A., Chubb, D.L., Veeraragavan, A., 2013. Steady state analysis of a storage integrated solar thermophotovoltaic (SISTPV) system. Sol. Energy 96, 33-45.

Gartling, D.K., 1978. Finite Element Analysis of Convective Heat Transfer Problems with Change of Phase.

Gau, C., Viskanta, R., 1984. Melting and solidification of a metal system in a rectangular cavity. Int. J. Heat Mass Transfer 27, 113-123.

Gilpin, M.R., Scharfe, D.B., Young, M.P., Pancotti, A.P., 2011. Molten Boron Phase-Change Thermal Energy Storage: Containment and Applicability to Microsatellites (Draft), DTIC Document.

Gschnaider, B., 2012. Contrib/swak4Foam.

Hsieh, C., 1995. Exact solutions of Stefan problems for a heat front moving at constant velocity in a quasi-steady state. Int. J. Heat Mass Transfer 38, 71-79.

Hu, H., Argyropoulos, S.A., 1996. Mathematical modelling of solidification and melting: a review. Modell. Simul. Mater. Sci. Eng. 4, 371.

Huang, R.K., Wang, C.A., Connors, M.K., Turner, G.W., Dashiell, M., 2004. Hybrid back surface reflector GaInAsSb thermophotovoltaic devices. AIP Conf. Proc., 329.

Huang, M., Eames, P., Norton, B., Hewitt, N., 2011. Natural convection in an internally finned phase change material heat sink for the thermal management of photovoltaics. Sol. Energy Mater. Sol. Cells 95, 1598 1603.

Kennedy, C.E., 2002. Review of Mid-to High-Temperature Solar Selective Absorber Materials. National Renewable Energy Laboratory Golden Colorado.

Lamberg, P., Siren, K., 2003. Analytical model for melting in a semiinfinite PCM storage with an internal fin. Heat Mass Transfer 39, 167176.

Lenert, A., Bierman, D.M., Nam, Y., Chan, W.R., Celanovic, I., Soljacic, M., Wang, E.N., 2014. A nanophotonic solar thermophotovoltaic device. Nat. Nano 9, 126-130.

Nakamura, S., Hibiya, T., 1992. Thermophysical properties data on molten semiconductors. Int. J. Thermophys. 13, 1061-1084. 
Rösler, F., Brüggemann, D., 2011. Shell-and-tube type latent heat thermal energy storage: numerical analysis and comparison with experiments. Heat Mass Transfer 47, 1027-1033.

Scharfe, D.B., Young, M.P., Gilpin, M.R., Webb, R., 2011. High Energy Advanced Thermal Storage for Spacecraft Solar Thermal Power and Propulsion Systems, DTIC Document.

Shockley, W., Queisser, H.J., 1961. Detailed balance limit of efficiency of $\mathrm{p}-\mathrm{n}$ junction solar cells. J. Appl. Phys. 32, 510-519.

Stone, K., Leingang, E., Drubka, R., Chubb, D., Good, B., Wilt, D., 1995. System performance of a solar thermophotovoltaic system for space and terrestrial application. In: Proceedings of the Intersociety Energy Conversion Engineering Conference, pp. 713-718.

Stone, K., Leingang, E., Drubka, R., Fay, T., 1994. Solar thermophotovoltaic power experiments at McDonnell Douglas. In: 29th Intersociety Energy Conversion Engineering Conference, Monterey, CA, pp. $1692-1696$.
Stone, K., Leingang, E., Kusek, S., Drubka, R., Fay, T., 1994. On-sun test results of McDonnell Douglas' prototype solar thermophotovoltaic power system. In: 1994 IEEE First World Conference on Photovoltaic Energy Conversion, 1994, Conference Record of the Twenty Fourth. IEEE Photovoltaic Specialists Conference-1994, IEEE, pp. 2010-2013.

Stone, K.W., Chubb, D.L., Wilt, D.M., Wanlass, M.W., 1996. Testing and modeling of a solar thermophotovoltaic power system. AIP Conf. Proc., 199.

Wernsman, B., Siergiej, R.R., Link, S.D., Mahorter, R.G., Palmisiano, M.N., Wehrer, R.J., Schultz, R.W., Schmuck, G.P., Messham, R.L., Murray, S., 2004. Greater than $20 \%$ radiant heat conversion efficiency of a thermophotovoltaic radiator/module system using reflective spectral control. IEEE Trans. Electron Dev. 51, 512-515.

Wilt, D., Wehrer, R., Palmisiano, M., Wanlass, M., Murray, C., 2003. Monolithic interconnected modules (MIMs) for thermophotovoltaic energy conversion. Semicond. Sci. Technol. 18, S209. 